\title{
VIOLÊNCIAS E ALCOOLISMO: ABORDAGEM BIOGRÁFICA EM ALCOOLOGIA E HERMENÊUTICA DO SUJEITO
}

\author{
Christophe Niewiadomski
}

\begin{abstract}
RESUMO. Meu propósito aqui será de mostrar como os fenômenos de violência, por vezes associados às condutas de alcoolização e aos problemas de álcool-dependência, não podem ser estudados fora do contexto sócio-histórico no qual eles se inserem. A abordagem aqui será centrada sobre a co-emergência e o reforço mútuo dos fenômenos intrapsíquicos e sociais nos quais as pessoas alcoólicas se encontram ao mesmo tempo tomadas e engajadas. Veremos, através do estudo de um exemplo biográfico com final dramático, que estes fenômenos de violência não são evidentemente reduzíveis aos fenômenos bioquímicos à que levam ao consumo patogênico de álcool. Em certo número de casos, a existência de enlaces sociopsiquicos se encontram na origem dos fenômenos de violência freqüentemente encontrados entre as pessoas alcoólicas. O método das histórias de vida em grupo constitui aqui uma abordagem privilegiada para tentar levar em conta e estudar estes fenômenos.
\end{abstract}

Palavras-chave: alcoolismo, violência, histórias de vida.

\section{VIOLENCE AND ALCOHOLISM. BIOGRAPHICAL APPROACH IN ALCOHOLICITY AND HERMENEUTICS OF THE INDIVIDUAL}

\begin{abstract}
The objective of this article is to show how the phenomenon of violence, sometimes associated with the behaviour of alcoholization and to alcohol-dependence problems, cannot be studied except in the socio-historic context in which they occur. The approach will be centered here on the co-emergence and mutual reinforcement of intrapsychic and social phenomena in which alcoholic individuals are simultaneously involved. We shall see, through the study of a bibliographical example, that these phenomena of violence are not reducible to the biochemical phenomena related to the pathogenic consumption of alcohol. In many cases, the existence of sociopsychic conflicts is at the origin of this type of violence. We shall see that the method of life histories in group is a privileged approach for studying these phenomena.
\end{abstract}

Key words: alcoholism, violence, life histories.

O álcool é um produto psicotrópico depressor do sistema nervoso central e cujos efeitos desinibidores concorrem à instalação de perturbações psíquicas variadas que podem conduzir a violência. Assim, os problemas de alcoolização são classicamente levados em conta em numerosas situações delituosas: homicídios, golpes e ferimentos voluntários e involuntários, crimes e delitos sexuais, maus-tratos, incesto, roubos, degradações, rebeliões e ultrajes diversos...
Além disso, o papel do abuso do álcool nas estatísticas de mortalidade é o suficiente para demonstrá-lo. Ele está envolvido em $30 \%$ dos acidentes de tráfego, em 10 a $20 \%$ dos acidentes de trabalho, em torno de dois terços dos homicídios voluntários e em mais de um quarto dos suicídios.

As manifestações violentas associadas ao consumo de álcool podem estar ligadas a fenômenos de intoxicação agudas ou crônicas. Independentemente da embriaguez simples que

* Mestre de Conferências em Ciências da Educação na Universidade de Lille 3. Membro da Associação Internacional das Histórias de Vida em formação e do grupo de trabalho "Romance familiar e trajetória social". Autor de "Histoires de vie et alcoolisme" (Histórias de vida e alcoolismo) publicado nas edições Seli Arslan em 2000, e de "Souci et soin de soi. Liens et frontières entre histoires de vie, psychothérapie et psychanalyse" (Atenção e cuidado de si mesmo. Laços e fronteiras entre histórias de vida, psicoterapia e psicanálise) co-dirigido por Guy de Villers e publicado nas edições L'Harmattan em 2002. 
raramente conduzem a fenômenos delituosos, a embriaguez patológica está frequentemente envolvida nos fenômenos de violência. Distinguimos habitualmente a embriaguez exitomotora (acompanhada de ataques de violências verbais ou psíquicas que conduzem algumas vezes a atos médico-legais), distímicas (que conduzem frequentemente a repetitivos suicídios) delirantes (associados a fenômenos de ciúme mórbido ou a delírios de perseguição). Em sua forma crônica, o alcoolismo leva a modificações profundas da personalidade: o controle pulsional é alterado e a imaturidade do eu, a dificuldade para tolerar as frustrações, a irritabilidade, a hipersensibilidade, o ciúme... irão afetar profundamente as relações do sujeito com seu entorno. Na esfera familiar, por exemplo, o cônjuge e os filhos, poderão tornar-se responsáveis da intemperança do sujeito e levar a comportamentos que conduzem às figuras do "carrasco doméstico" amplamente descritos na literatura especializada. As crises de violência, associadas à miséria afetiva e por vezes econômica levam então a uma desorganização familiar extrema. Entretanto, ao lado destes quadros trágicos, está uma violência mais sutil frequentemente ligada à preservação do segredo concernente à intemperança de um dos membros do sistema familiar. Muito frequentemente, as relações nestas famílias se desenvolvem "dentro de quatro paredes", a fim de se proteger do olhar provindo de um meio "que não pode compreender". A comunicação no seio destas famílias se estabelece então sobre um modo hiperafetivo onde reprovação e compaixão alternam-se em relação à pessoa que sofre de álcool-dependência. Cada um "sofre então com o sofrimento do outro" e a comunicação aparece marcada por numerosas mensagens paradoxais. Além do sofrimento dos adultos, as crianças crescem então em um clima de desqualificação social e de insegurança marcado por perturbações da identificação e fenômenos de vergonha cujos efeitos, nós o veremos no exemplo clinico, podem ter repercussões patogênicas transgeracionais.

Além disso, acrescido a estes efeitos relativos à esfera familiar, a sociedade contemporânea se confronta com um número cada vez maior de pessoas com uma perda de referências identitárias que preparam a cama das condutas adictivas (Niewiadomski, 2002). Entretanto, se a alcoolização tem um papel desinibidor no plano bioquímico e favorece uma liberação pulsional, “este esquema simples e sem dúvida exato, não nos mostra de forma alguma porque e em direção a que os instintos em questão deveriam ser liberados" (Debray, 1994, p. 80). Assim, em alguns adolescentes ou jovens adultos, o álcool é hoje utilizado em uma perspectiva desesperada e reivindicatória face a uma organização social que lhes propõem apenas perspectivas existenciais vagas e insatisfatórias. Esta alcoolização, brutal e massiva, vai lhes permitir se afirmar e "ajustar as contas" algumas vezes de maneira muito violenta em relação a uma sociedade elitista da qual eles se sentem excluídos. Os fenômenos de violência coletiva que pudemos observar, por exemplo, na Inglaterra e em outros lugares, em alguns meios esportivos, representam, em parte, a expressão destas dificuldades identitárias e sociais.

\section{ABORDAGEM BIOGRÁFICA E ACOMPANHAMENTO TERAPÊUTICO EM ALCOOLOGIA ${ }^{1}$}

Desde a metade dos anos $40^{2}$, o acompanhamento terapêutico em alcoologia se apóia de maneira eletiva sobre o conceito biomédico de “doença alcoólica". Assim, o alcoolismo é atualmente considerado como surgindo de uma perturbação adictiva cuja característica essencial, segundo a célebre formula de Fouquet (1956), se organiza em torno "da perda de liberdade de se abster de álcool”. Além das diferenças de categorização empregadas, a maioria dos modelos clínicos atualmente utilizados em alcoologia tende a promover a hipótese teórica de um paciente atingido de uma "doença de álcooldependência". Este paradigma, amplamente dominante em nossa época, organiza de fato o que chamamos de modelo biomédico do alcoolismo. Este afirma a existência de um conjunto de perturbações agrupadas sob o termo genérico de "doença alcoólica", que se segue a uma fase prodrômica variada segundo os sujeitos, e cuja fase de estado se caracteriza por uma doença crônica, irreversível, e cujo único tratamento possível reside na abstinência total e definitiva de toda bebida alcoólica.

\footnotetext{
1 Para maiores detalhes, ver a respeito em: Niewiadomski C. (2000) Histoires de vie et alcoolisme. Paris: Seli Arslan.

2 Jellineck, E. M.(1946). Phases in the drinking history of alcoholics. New Haven: Hillhouse Press. Jellineck E.M. (1960). The disease concept of alcohokism. New Haven: Hillhouse Press.
} 
No plano clínico, este paradigma teórico tende a favorecer o desenvolvimento de estratégias de cuidados referidos à noção de "psicoterapia educativa". Esta abordagem visa integrar o benefício de técnicas de psicoterapia de grupo e a uma abordagem centrada na informação sobre a doença alcoólica. Ao lado de vantagens evidentes que permitem ao sujeito romper com o tóxico e se ressocializar, alguns efeitos indesejáveis irão por vezes alterar os benefícios esperados neste período de remanejamento existencial. Assim, observamos algumas vezes uma verdadeira alienação do sujeito a um traço de pertencimento (ser um "doente alcoólico") que vem definir abusivamente sua identidade e que pode se opor duradouramente ao processo emancipatório perseguido. Nesta perspectiva terapêutica, o profissional que tem sob sua responsabilidade o paciente "sabe" o sentido daquilo que se mostra, isto é uma conduta de intemperança que transborda as possibilidades de regulação do sujeito. O "terapeuta especialista" pode então, com toda boa-fé, impor seus próprios esquemas de compreensão da situação apoiando sua ação sobre modelos teóricos biomédicos a fim de promover um tratamento supostamente apropriado ao sofrimento psíquico daquele que formula uma demanda de cuidados.

Todavia, uma outra via, complementar a primeira, pode ser considerada apoiando-se sobre a metodologia das histórias de vida. Seis a oito pessoas alcoólicas voluntárias compõem geralmente grupos de trabalho que se desenvolvem em um período de em torno três meses quando da internação em instituição especializada. Vários períodos organizam o trabalho proposto: uma seqüência de contratualização, depois uma fase de enunciação e enfim um período de trabalho coletivo sobre os enunciados produzidos por cada membro do grupo. A enunciação oral do relato de vida, vai aqui constituir como algo prévio para a escrita de um texto, operando uma primeira reorganização dos materiais biográficos, depois vai dar lugar a múltiplos "vais e vens" entre produção oral, trocas com os outros participantes e trabalhos de escrita com vistas à de construção de sentido. Além disso, laços podem aqui ser tecidos entre um ramo relativamente recente da sociologia, a sociologia clínica e o trabalho biográfico concernente a fenômenos de violência encontrados entre pessoas álcool-dependentes. A sociologia clínica é a busca que se interessa pelas interações entre os processos psíquicos e os processos sociais. Sua especificidade não se apega tanto a seu objeto de estudo quanto a seu modo de apreensão dos fenômenos estudados. Esta abordagem rompe com uma abordagem sociológica mais tradicional. Com efeito, a fim de produzir resultados com pretensões "científicas", a sociologia tentou adaptar a seus objetos de pesquisa, ferramentas de avaliação quantitativa. Nesta perspectiva, o discurso do sujeito, necessariamente marcado de subjetividade, não é considerado como suficientemente confiável para modelizar a realidade social. A sociologia clinica, ao contrário, procura levar em conta esta subjetividade do ator social. Assim, ela se inscreve em uma corrente de pensamento sociológico que postula que as estruturas sociais nas quais evoluem os atores podem apenas ser compreendidas na medida em que se leva em conta a maneira pela qual estes mesmos atores vivem e representam para si mesmos estas estruturas. Recusando compartimentos disciplinares, a sociologia clinica procura evitar dois perigos: o "psicologismo", visão que privilegiaria a análise dos fenômenos intrapsíquicos em detrimento do reconhecimento das estruturas sociais nas quais vivem os indivíduos, e o "sociologismo" que consideraria o sujeito como o produto de determinantes sócio-históricos que o ultrapassam e sobre os quais ele não teria nenhum conhecimento. Para De Gaulejac (1993):

\begin{abstract}
a sociologia clínica tem como objeto desemaranhar os nós complexos entre os determinismos sociais e os determinismos psíquicos nas condutas dos indivíduos e dos grupos assim como nas representações que eles se fazem destas condutas. Ela se inscreve no centro destas tensões entre objetividade e subjetividade, entre estrutura e ação, entre individuo produto sócio-histórico e o individuo criador de história, entre a reprodução e a mudança, entre as dinâmicas inconscientes e as dinâmicas sociais(...) (p. 14).
\end{abstract}

Ora, desde há alguns decênios, transformações sociais cada vez mais rápidas levam alguns atores sociais a se deslocarem por vezes consideravelmente no espaço das posições sociais, descritas por Bourdieu (1979). Assim, inúmeras pessoas não se encontram mais na estrita reprodução das posições tradicionalmente ocupadas desde há muitas gerações em seu meio familiar. Outros ainda, tais como os jovens adultos citados acima, experimentam grandes dificuldades para "encontrar seu lugar" numa sociedade fortemente marcada pelos efeitos cruzados da mobilidade social, da aceleração do tempo e do individualismo. 
Para De Gaulejac (1897), algumas pessoas confrontadas a estas dificuldades podem apresentar distúrbios psíquicos inteiramente particulares que nascem na articulação e no reforço mútuo de conflitos que são do registro do social e de conflitos que são do domínio do "intra-psíquico". É esta constatação que o levou a propor o conceito de "neurose de classe". Sobre estas bases, trabalhos realizados na área da alcoologia mostraram por outro lado que a "queda no alcoolismo poderia se operar em momentos biográficos onde as contradições - incluindo contradições ligadas à trajetória social do indivíduo - viriam se enlaçar, se potencializar, se sobre- determinar" (Legrand, 1993, p.227) ${ }^{3}$.

Percebemos assim o quanto a abordagem biográfica pode permitir as pessoas alcoólicas operarem um retorno reflexivo sobre sua trajetória pessoal e identificarem mais claramente determinantes sociais que algumas vezes influenciaram fortemente o curso de suas vidas e seu recurso ao álcool. Nos grupos de trabalho que utilizam a historia de vida em alcoologia, a intenção se organiza em torno da reaproximação de sua historia por cada um dos participantes e não a partir da referencia unívoca de um discurso médico-tecno-científico sobre o alcoolismo. A via privilegiada aqui é a de apropriação pelo sujeito de seu poder de "biografização", isto é, de sua capacidade de "tomar forma", via trabalho reflexivo que vai permitir o trabalho de narração e de troca a partir de sua história pessoal. Para Delory Momberger (2003), a biografização

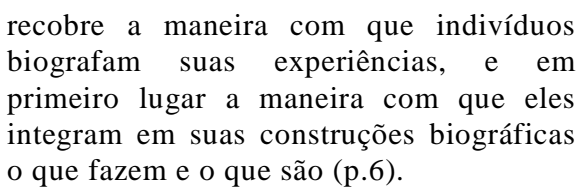

nas diferentes esferas de atualização existenciais, pessoais e sociais, que eles encontraram até então. Esta narrativa biográfica, co-interpretada com os outros participantes, permitirá então ao sujeito construir uma hermenêutica de sua história de vida, abrindo a um "projeto de si" que, ao integrar-se ao projeto de abstinência, não se limitará a este último.

Examinemos doravante, através de um exemplo clinico que articula fenômenos psíquicos e sociais, as formas que podem tomar a violência operada ou

3 Ver também: Legrand, M. (1997). Le sujet alcoolique: essai de psychologie dramatique. Paris: Desclée de Brouwer. sofrida entre pessoas atingidas pela álcooldependência.

\section{JACKY ${ }^{4}$ : UMA NARRATIVA DE VIDA MARCADA PELA VIOLÊNCIA E "PELO ABANDONO".}

Jacky é um homem de cerca de trinta anos. Ele foi enviado à uma instituição especializada no tratamento de alcoolismo por seu médico. Ele sofre de uma álcool-dependência complicada de embriaguez patológica violenta que o levaram a numerosos problemas judiciais. A carta de encaminhamento ${ }^{5}$ que ele apresenta por ocasião de sua admissão, relata uma seqüência de fracassos repetitivos tanto no plano profissional quanto no plano afetivo. $\mathrm{O}$ exame médico realizado na entrada mostra poucos sinais de intoxicação alcoólica crônica, mas uma instabilidade nervosa importante e uma estrutura de personalidade do tipo psicopático que deixa o psiquiatra de plantão cuidadoso quanto à capacidade deste paciente de se inscrever num programa de cuidados.

Muito rapidamente, Jacky assume o papel de "líder ansiógeno" no grupo historia de vida do qual ele quis participar ${ }^{6}$. Ele investe, entretanto, com energia no trabalho de escrita solicitado, mas experimenta, num primeiro momento, grandes dificuldades para estruturar cronologicamente sua narração. Ele evoca "momentos fortes" de sua história de um modo extremamente dramático, relatando em fragmentos uma história pessoal entrelaçada de "catástrofes". A problemática familiar que ele expõem é manifestadamente "pesada", mas o grupo história de vida parece lhe convir e realiza um espaço de expressão e de troca que ele julga satisfatório: "É a primeira vez que eu posso realmente falar de mim e ser escutado" ele esclarece.

4 Este exemplo clínico advém da obra "Histórias de vida e alcoolismo" citada acima.

5 Carta que justifica o pedido de cuidados de um doente e endereçada pelo médico que o trata, para a instituição especializada encarregada de o acolher para uma hospitalização. Além das precisões médicas que dizem respeito ao estado de saúde do paciente, este documento contém frequentemente um curto relato em relação com sua trajetória biográfica.

6 Todos os participantes destes grupos são voluntários e se engajam neste trabalho após uma ou várias entrevistas explicativas e sobre a base de um contrato explicito entre $o$ animador e os membros do grupo. 
Jacky é o mais velho de uma família de dois filhos. Seu pai, que trabalha com transporte de mudanças, é também alcoólico. Ele seguiu um tratamento de desintoxicação na instituição quinze anos antes. Este tratamento não teve os efeitos esperados e o pai de Jacky continua a se alcoolizar de maneira episódica, mas massivamente, o que levou a grandes dificuldades profissionais $\mathrm{e}$ familiares. Com efeito, o pai, visto como o "mau sujeito", é praticamente cortado de sua família que parece se reduzir a um tio e uma tia de Jacky.

Logo de início, Jacky explica que o alcoolismo de seu pai parece ter tido repercussão muito importante sobre seu próprio consumo de álcool. Jacky é muito ligado a sua irmã mais nova, que tem desde o nascimento graves problemas de saúde. Esta irmã, mais jovem alguns meses, é transformada em sua meia-irmã. Ele descobrirá a natureza dos laços familiares que os unem por ocasião de uma discussão com seu pai. Jacky explica o choque sentido, quando ele tinha dez anos, quando ele descobre de uma só vez que a pessoa que ele acreditava ser sua mãe é na verdade sua mãe adotiva e que sua irmã é sua meia-irmã. Sua verdadeira mãe deixou seu pai quando ele tinha dois anos, e o pai o dissuadia por muito tempo de procurar fazer contato com sua mãe genética que, diz ele, o "abandonou" a que ele descreve como "dura e severa".

Jacky falará relativamente pouco das repercussões do alcoolismo de seu pai em sua infância, mas, expressará pudicamente que "não era engraçado todos os dias". Mais que isso, ele toma bem claramente a defesa de seu pai, que ele descreve como uma "vitima" de sua família.

$\mathrm{Na}$ adolescência, seu pai o leva frequentemente com ele aos bares. Jacky é feliz de seguir seu pai, e ele tem o sentimento de que seu pai o autoriza assim a participar deste ambiente com bastante "camaradagem viril" de seus colegas de trabalho: "eram brutos". Como o álcool fazia "parte do cenário", seu pai o incitava a se alcoolizar:

Em relação ao meu pai, é que desde a idade de 14 anos, ele me levava aos bares. Bom, eu conhecia o meio dos transportes de mudanças, é isso aí, eu saía bastante com seus companheiros, é isso... então no início, era um copo, apenas um pequeno copo, aos pequenos goles, e depois... isso durou talvez seis meses assim, e depois... foi aumentando a dose, e tal! Com a idade de dezesseis anos, então aí, já era uma caneca.
Ao mesmo tempo, e durante alguns meses, o pai de Jacky tem uma ligação extraconjugal que torna ainda mais precário o equilíbrio familiar. $\mathrm{O}$ pai volta para casa cada vez mais frequentemente alcoolizado e as discussões tornam-se comuns. É nessa época que Jacky começa a desertar da escola e que ele "começa a fazer besteiras com os amigos". Diante das dificuldades crescentes, tanto com o filho quanto com o pai, a madrasta de Jacky fica cada vez mais "passada pelos acontecimentos". Ora, por ocasião de uma mudança profissional efetuada pelo pai, e sob conselhos de um tio e de uma tia de Jacky, a madrasta contribuirá para a colocação de Jacky "em uma casa de correção". Jacky não terá jamais rancor de sua madrasta que, diz ele, "fazia realmente tudo o que ela podia". Por outro lado, ele desenvolve um ódio tenaz em relação a seu tio e sua tia, "burgueses conformistas", hostis a seu pai, e que "tinham que se meter só com suas coisas". Jacky permanece dois anos nesta instituição onde, diz ele, aprende, sobretudo, a violência e o ódio. Jacky aproveita suas saídas para fazer "o maior número possível de besteiras" e para se alcoolizar, algumas vezes, massivamente.

Jacky dá poucos detalhes sobre estas "besteiras" da época, mas explica que ele era um adolescente particularmente difícil e que era bastante briguento. Ele descreve muito bem o sentimento de onipotência que ele sentia quando estava alcoolizado e o desejo que tinha de bater-se com toda pessoa que cruzava seu caminho. Apesar de seus problemas com a disciplina, Jacky consegue ainda assim um $\mathrm{CAP}^{7}$ nesta instituição. Ao sair, com 17 anos, ele começa a trabalhar na empresa onde seu pai está empregado. Jacky faz imediatamente um vínculo entre seu início profissional e "a queda no álcool". Ele escreve a este respeito:

Após meu CAP eu fui contratado
diretamente para trabalhar com mudanças.
Enfim, mais exatamente, foi meu pai que
me fez contratar. E a partir daí, foi a
decadência, foi a queda. Eu tinha 17 anos
e meio. No início, tudo ia bem, eram
pessoas que eu conhecia. À noite, quando
a gente tinha acabado o serviço, a gente ia
todos tomar um trago. Mas por vezes, era

7 Certificado de aptidão profissional. Trata-se de um diploma nacional com fins profissionais e técnicos obtido após dois anos de estudos. Este diploma atesta um primeiro nível de qualificação profissional e permite aos seus titulares ocupar empregos de operários qualificados. 
também na casa de clientes, no momento do lanche da manhã, ao meio-dia, no restaurante e depois à noite no bar. Então algumas vezes era pouco, outras vezes era bastante... e às vezes era bem mais que bastante... Até que meu pai acabou sendo despedido, as coisas iam mais ou menos, eu controlava, mas aí, foi a debandada. Eu tinha dezenove anos. Meu pai foi mandado embora porque ele teve um problema de álcool com seu carro. Ele não tinha mais a carteira, e o patrão não tinha então mais necessidade dele. Naquele momento me deu um flash e eu comecei a me questionar. As pessoas me diziam: "Teu pai foi mandado embora, preste atenção... porque você corre o risco de estar no lote". $E$ eu não sei o que aconteceu, era ainda pior, eu bebia ainda mais que antes. E durante mais de seis meses, eu bebi todos os dias, sete dias por semana.

Quando os membros do grupo o interrogam sobre este período particular, Jacky evoca ao mesmo tempo a lembrança do "medo de ser mandado embora", mas também a tentativa de aproximação com sua mãe biológica:

Eu tinha medo de ... medo de ser mandado embora já. É o que aconteceu, aliás, em seguida... mas é também naqueles momentos que minha mãe começou a ter contato com meu pai, minha verdadeira mãe hein!... porque ela pedia para me ver...

Nesta época, Jacky deixou em seguida o domicilio de seu pai e passou a viver em um pequeno apartamento alugado. Uma noite, ele recebeu um telefonema de sua mãe. Esta, depois de mais de vinte anos de silencio, desejava encontrá-lo sem que uma razão para isso seja explicitamente dada. Jacky parte então para encontrar sua mãe e vai morar com ela durante um mês. Ela mora em um belo apartamento no centro da cidade e leva uma vida confortável no plano financeiro. Entretanto, este encontro não preenche suas expectativas:

eu disse a mim mesmo que iria vê-la para conversar. E depois, como tinham me dito que ela era dura, e tal... digamos que isso me preparou um pouco. Aí eu quis julgar por mim mesmo. Eu cheguei lá no alto e depois eu vi que ela era realmente assim, dura pô! Eu estava decepcionado porque eu percebia que no final das contas eu era... nada para ela pô!

Após esta estadia, Jacky volta para sua casa e se encontra de novo confrontado com as dificuldades que trazem suas alcoolizações. Ele não consegue mais se levantar para ir ao trabalho e multiplica os atos de violência nos bares, o que o leva várias vezes a passar temporadas na prisão. Além disso, ele acumula dívidas, não paga mais suas contas e não se alimenta mais corretamente. Com os conselhos de sua madrasta, e após vários meses de "desventuras" cada vez mais desestruturantes, Jacky opta por uma cura de desintoxicação num meio especializado.

\section{COMENTÁRIOS E HIPÓTESES DE TRABALHO}

Independentemente da separação parental precoce, o meio familiar no qual Jacky cresceu é o teatro de numerosos acontecimentos que conflitivos. As relações do pai com sua família são extremamente tensas. $\mathrm{O}$ pai tem manifestamente grandes dificuldades com o álcool e parece que este problema, sem estar claramente na origem da desarmonia familiar, não the seja absolutamente estranho.

Convém sublinhar que na época em que eu trabalhei com Jacky, eu não estava familiarizado com trabalhos referentes à corrente da sociologia clinica. Então, sem dúvida, eu não orientei suficientemente a exploração biográfica nesse sentido. Assim, um analisador essencial da interpretação dos dados fornecidos pela narrativa de Jacky não pode ser mobilizado no "aqui agora" do trabalho do grupo. Ora, percebem-se aqui como os elementos subjacentes de classe vêem se estabelecer com a trajetória singular de Jacky. Se os dados recolhidos junto à Jacky me parecem hoje muito parcelares quanto ao registro, é possível, entretanto aprofundar a análise a posteriori sugerindo algumas hipóteses complementares sobre os fatores de classe que atravessaram o sistema familiar no qual ele evoluía.

Os propósitos tidos por Jacky a respeito de seu tio e de sua tia materna e em relação as condições de vida de sua mãe, indicam claramente um pertencimento social à burguesia ainda que o pertencimento social do pai apareça muito mais referido a classe popular. Jacky não nos disse nada do encontro de seus pais, nem de seus pertencimentos sociais respectivos na época da constituição do casal, mas é possível que a 
diferença de hábitus de classe $^{8}$ entre os dois cônjuges tenha podido participar da falência de sua relação ${ }^{9}$. Na economia relacional de um casal, os implícitos sociais não devem ser subestimados. O indivíduo é sempre o produto de uma história social que sobredetermina sua maneira de se situar na sua relação conjugal. Assim, um cônjuge habituado a se comportar a partir de hábitus populares quanto a sua relação com o dinheiro, com a alimentação, com a escolha de programas televisivos, lazeres... poderá "irritar" consideravelmente uma parceira mais habituada a uma visão da existência marcada por hábitos diferentes, qualquer que seja a intensidade do afeto que se tenham os esposos As relações de classe, em um casal ou em outro lugar, se organizam de tal maneira que induzem relações de poder fundamentalmente não paritárias: "as boas maneiras", o "bom gosto", a conveniência, a distancia intelectual... logo as práticas culturais socialmente valorizadas não são, no espaço das posições sociais, o apanágio das classes sociais chamadas de "laboriosas". Além disso, o peso do olhar familiar (pais, irmãos, irmãs...) sobre a escolha de um cônjuge que não pertence ao mesmo meio sociocultural pode por vezes complicar consideravelmente as relações do casal. Se nada sabemos aqui das motivações da mãe biológica de Jacky quanto à escolha de seu cônjuge, podemos, todavia supor que na história do casal, fatores de classe intra e interfamiliares puderam participar do desencadeamento ou do reforço das condutas de

8 Para Bourdieu (1979), o espaço social é constituído de posições que se definem umas em relação às outras a partir de um conjunto de recursos que serão objeto de lutas de apropriação pelos atos sociais. Estes recursos são chamados de capitais. $\mathrm{O}$ autor os subdivide em várias categorias: capital econômico, capital social (rede relacional dos atores), capital simbólico (prestigio, reputação...) e capital cultural, ele próprio subdividido em capital cultural institucionalizado (diplomas), capital cultural objetivado (bens culturais), e capital cultural incorporado (hábitos). A repartição destes capitais no campo social organiza três grandes classes sociais: a classe popular, a classe média, e a classe dominante. Estas classes sociais estão estreitamente dependentes umas das outras mas se opõem pelas distancias que finalmente as separam. Hábitos particulares correspondem a estas classes sociais e sobredeterminam o comportamento dos atores no espaço das posições sociais. Bourdieu define os hábitos como sistemas de disposição incorporados, interiorizados pelos atores sociais a favor de uma familiarização precoce e intensiva, de tal forma que estes dispositivos adquiridos podem aparecer "innées".

9 Um trabalho em torno da árvore genealógica, suporte utilizado pelos sociólogos clínicos, teria sem dúvida permitido objetivar estas dimensões. alcoolização do pai, que precipitaram a ruptura: “A lógica da distinção homologa a dominação. Para $P$. Bourdieu, o que faz a força desta influencia, é que ela está submersa no mais profundo dos psiquismos, e dos corpos. As estruturas sociais estão de alguma forma "decalcadas" sobre estruturas mentais"(Cabin, 2002, p.31). Além disso, é freqüente constatar quanto a dupla vergonhadesprezo tem um papel essencial no desenvolvimento dos processos de álcooldependência. Jean Maisondieu esclarece a este propósito:

No inicio do alcoolismo, há a vergonha, este sentimento penoso de sua inferioridade, de sua indignidade ou de sua humilhação diante do outro, de sua diminuição na opinião dos outros. Eu não conheço um alcoólico em quem falta este afecto doloroso (...) Encolhido em sua vergonha, ele se fiou no álcool até não poder mais passar sem ele e até ter vergonha de se ter tornado o que ele se tornou: um alcoólico (Maisondieu,1992, p.15).

Pode-se propor aqui a hipótese de uma "colagem" entre as dificuldades interpessoais do casal e os efeitos da diferença de classe entre o pai e mãe de Jacky. Estes últimos puderam, com efeito, nutrir o sentimento de desqualificação social do pai, se ligar com outros fatores de indignidade suposta e levar assim a fuga no álcool, reivindicada paradoxalmente em seguida como uma maneira de resistir à dominação social de sua esposa e de sua família moldados pelos hábitus de uma "ordem burguesa" que tentava se impor no próprio seio do casal. Se não sabemos nada aqui da complexidade das motivações ligadas a "resistência" do pai, resta que a "orgulho" do alcoólico teve provavelmente aqui um papel essencial. Ao invés de admitir suas dificuldades, muito frequentemente percebidas como fraquezas, o alcoólico se inscreve, com efeito, em uma lógica do tudo ou nada que o fecha neste circulo vicioso da dependência: "antes a morte que a desonra de confessar"(Maisondieu,1992, p.36) esclarece ainda Jean Maisondieu. Esse orgulho enraíza talvez aqui a defesa face à humilhação e conduz o pai de Jacky a continuar suas alcoolizações.

Após a separação da mãe biológica de Jacky, o pai, sempre em contato com a família dela (o tio e a tia), se alcooliza regularmente, por vezes massivamente, e ele torna a existência difícil no seu entorno. Jacky logo evoca episódios de violência familiar contemporâneos a estas alcoolizações paternas. 
Entretanto, é interessante constatar o processo de identificação do filho com a figura paterna. $\mathrm{Na}$ adolescência, Jacky, "pequeno homem em evolução", segue com um prazer evidente seu pai nos bares, e ele se integra a seu universo de amigos e profissional graças aos ritos de alcoolização próprios a este meio. Jacky segue o exemplo e os conselhos de seu pai que o inicia a um modo relacional onde o álcool ocupa um lugar importante. E de fato, para Jacky, "é preciso beber para ser um homem" e poder assim ser admitido no círculo dos "grandes". O álcool parece aqui vir preencher a função de um "objeto bom" (Klein, 1948) que permite o acesso ao mundo dos adultos, fonte imaginária de emancipação de escolha e de domínio de seu destino.

Entretanto, por ter passado pela dolorosa experiência por ocasião das desordens familiares induzidas pelas alcoolizações do pai, Jacky sabe que o álcool não tem somente aspectos positivos. É um tóxico que pode também ter o papel de "objeto mau". Mas parece que nas representações de Jacky, este estatuto de "objeto mau" não está diretamente ligado ao objeto álcool enquanto tal. Para Jacky, se seu pai se alcooliza, é porque ele é uma "vítima" de sua família e mais particularmente de sua fração "burguesa" que o trata como um paria. Nesta perspectiva, o consumo de álcool do pai tem também valor de uma estratégia "de rebelião" em relação a uma ordem familiar exterior que visa excluí-lo. Além disso, mas de maneira mais inconsciente, as condutas de alcoolizações patológicas do pai angustiam Jacky, que se interroga sobre as motivações profundas de seu pai:

\footnotetext{
Ele, o álcool, era... eu não sei... eu nunca procurei saber... enfim sim, mas não se podia discutir com ele... talvez agora eu pudesse the perguntar o porquê... Antes, eu lhe perguntava... calmamente... mas isso o deixava nervoso... eu me pergunto se isto está ligado a minha irmã, ou a minha mãe... ou a mim talvez, ou a mim... talvez isso o fizesse se chatear de me ter feito... eu não sei.
}

Finalmente, como é freqüente nas famílias em que um dos pais é álcool-dependente, Jacky estima que ele possa ter sido "responsável" pelo drama de seu pai, só pelo fato de existir. Frente a este sentimento de culpa dificilmente suportável, Jacky é obrigado a racionalizar e "desculpar" antecipadamente a conduta de seu pai. Ele vai assim tentar negar este sentimento de culpa favorecendo a tese do encarniçamento da "malvada família burguesa" sobre o pai.

Ora, ao menos três acontecimentos na história de Jacky vão contribuir a "aferrolhar" ainda mais as coisas e fechá-lo em uma lógica de dependência de álcool:

1) Em primeiro lugar, o episódio do internamento "em casa de correção" parece ter tido um papel fundamental. Nesta época, o clima familiar está particularmente desastroso e Jacky, desestabilizado por esta situação, começa “a fazer bobagens". O tio e a tia, alertados pela madrasta incitam esta última a colocá-lo em uma instituição especializada. Jacky dá pouca precisão sobre as circunstancias exatas deste internamento, mas ele guarda uma lembrança bastante traumática deste período e vai desenvolver durante o internato uma animosidade extrema com relação a seu tio e sua tia. Como seu pai, Jacky estima estar presentemente em ruptura com sua família materna. Ele odeia literalmente este tio e esta tia, considerados como porta-voz de uma família "bem pensante", também reflexo da sociedade "burguesa". Jacky exprime "que eles se metiam onde não eram chamados", e que não podiam compreender os motivos de seus atos e dos de seu pai. Revoltado, Jacky retomará doravante o mesmo "combate" de seu pai contra os "burgueses" sem, todavia medir todas as implicações ligadas a essa escolha.

Assim, para Jacky, o consumo de álcool é muito rapidamente marcado por uma relação complexa de identificação com o pai e de "fidelidade" a sua trajetória. Podemos facilmente encontrar os traços dessa relação de identificação nos acontecimentos ulteriores.

2) Em segundo lugar, a escolha profissional de Jacky ao término de sua escolaridade parece bastante característica. Com efeito, desde sua saída da instituição onde ele foi internado e quando ele conseguiu obter um certificado de aptidão profissional, esse último sem relação com a profissão de seu pai, Jacky deseja trabalhar com ele na mesma empresa. Jacky explica muito bem o laço que parece existir entre o início de seu problema de dependência ao álcool e este trabalho. Mais exatamente, é importante constatar que é no momento em que seu pai é despedido que Jacky, em um processo de identificação que poderíamos qualificar de mortífero, começa a encontrar "inexplicavelmente" dificuldades cada vez 
maiores com o álcool. Assim, ao invés de limitar seu consumo e ainda mais que os fenômenos de dependência fisiológica ao tóxico não parecem ainda instalados, Jacky, pelo seu desejo de "fidelidade" a sua representação do cenário paterno, se encontra na impossibilidade de reduzir seu consumo de álcool. Evidentemente ele tem medo de ser demitido. Mas, como seu pai, isso se dá por ser ele uma "vítima revoltada e insubmissa" face à sociedade burguesa e a suas regras. A este propósito, Jacky explica, aliás, muito bem o sentimento de poder experimentado nos momentos de ingestão de álcool e a necessidade "de contestar" tudo o que representa a sociedade "bem pensante".

3) Enfim, o terceiro acontecimento de importância constitui o encontro de Jacky com sua mãe e a retomada dramática de uma incerteza profunda sobre seu próprio valor. Em um plano estrutural, é provável que Jacky sofra de uma neurose abandônica $^{10}$ Ora, esta mãe, que vive com um conforto ao qual ele não está habituado e cujos hábitos burgueses estão muito distantes dos seus, não o aceita como ele o imaginava. Podemos imaginar o traumatismo vivido por Jacky que se percebe então como rejeitado por uma mãe que já lhe tinham afirmado "ela o havia abandonado" na sua infância. Esta vivência singular deve aqui ser colocada em relação com as características dos fenômenos de individuação-separação encontrados nas pessoas alcoólicas:

Onde muitos vivem um momento de triunfo, quando descobrem que podem viver sem sua mãe, os futuros alcoólicos sofrem um choque que os aterra, porque eles percebem que sua mãe pode viver sem eles. Em um instante, eles se tornam órfãos e a morte entra em suas almas. (Maisondieu,1992, p.109).

10 Em 1950, os psicanalistas Charles Odier e Germanie Guex descrevem sob o termo de "neurose de abandono" uma síndrome associando a angústia, a agressividade e a desvalorização de si. Muito contestada no plano estrutural e clinico, a neurose de abandono não é considerada como uma neurose no sentido clássico do termo (isto é, no sentido freudiano). Tratar-se-ia antes de uma posição face à existência, própria de algumas personalidades geralmente classificadas no campo dos "estados limites" (border line). As referencias à psicopatia e as personalidades anti-sociais são freqüentes quando evocamos o termo de neurose de abandono.
Ora, esta "rejeição" da mãe pode ser colocada em perspectiva com os fatores de classe citados acima e, que também ai puderam ter um papel importante na relação entre esta mãe e seu filho. Apesar da boa vontade de ambos, eles não possuem os mesmos hábitus, as mesmas referencias culturais e sociais. Em poucas palavras, eles não se encontram sobre o mesmo "planeta social" o que torna provavelmente a comunicação difícil e sem dúvida fonte de mal entendidos que virão, também, a enlaçar com uma história familiar já delicada. Assim, laços afetivos suficientemente positivos e continentes não poderão se estabelecer entre eles e contribuir, assim, para nuançar o processo de identificação ao pai. Bem ou mal, Jacky se decide no constato seguinte: ele pensa não ser nada para sua mãe. Esta dolorosa constatação vai assim legitimar ainda um pouco mais a escolha identificatória com a trajetória paterna: "tudo o que tinham me falado sobre ela era verdade, eu não tenho outra escolha senão seguir a via traçada por meu pai”.

Como explicado anteriormente, Jacky se investiu com muita energia e aplicação no grupo história de vida ao qual ela participou. Assim, parece que o trabalho que ele produziu no decorrer das sessões lhe permitiu progressivamente se "descolar" um pouco do cenário ao qual ele era tão apegado e que podemos resumir como se segue: "Como meu pai, e apesar das consequiências, eu sou e continuarei uma vitima da sociedade, o que legitima e desculpa por antecedência todos os meus excessos".

Jacky começa assim a melhor perceber os processos em andamento em sua história pessoal e se questiona cada vez mais sobre "o que ele pôde fazer daquilo que a vida fez dele". Em particular, sua violência passada em relação ao outro o interroga. O grupo também o incitará a refletir sobre a atitude de seu tio e de sua tia no momento de seu internamento na "casa de correção". Um dos membros do grupo formula muito claramente a hipótese segundo a qual este internamento podia ser uma verdadeira medida de proteção para Jacky não uma "intriga" familiar destinada a separá-los um pouco mais, ele e seu pai. Mas, quando Jacky começa a poder aceitar a examinar estes argumentos sem lhes opor uma rejeição sistemática, uma ligação telefônica de sua madrasta reativará sua animosidade com relação a seu tio e sua tia. Jacky vai se calar sobre o conteúdo exato desta conversa, mas ele evoca uma "história de família" que necessita de sua presença a fim de proteger os 
interesses de sua madrasta e de sua meia-irmã. Apesar dos conselhos de prudência dos membros do grupo e dos cuidadores da instituição, Jacky porá fím a sua estadia e deixará prematuramente o grupo. Oito meses após sua saída, eu soube, pela imprensa, de seu falecimento em condições dramáticas: durante uma rixa na qual o álcool parece ter tido um papel importante, ele é mortalmente esfaqueado.

\section{CONCLUSÃO}

A história de Jacky representa no meu ver, um caso exemplar por várias razões. Em primeiro lugar, este exemplo clínico mostra quanto a compreensão dos fenômenos de violência características das problemáticas de embriaguez patológicas não podem ser considerados sem tomar em consideração a articulação biográfica entre processo psíquico e contexto sociológico no qual eles se inscrevem.

Em segundo lugar, a conclusão dramática de sua historia mostra quanto o risco "d'acting out", sempre presente no trabalho de acompanhamento das pessoas alcoólicas, e mais particularmente junto a pacientes muito impulsivos, tais como Jacky, coloca em prova a "fúria de se curar" que habita os pacientes.

Em terceiro lugar, se falta lugar aqui para evocar o impacto do trabalho do grupo sobre as resistências do sujeito, resta que este ponto deve ser interrogado e incitado à prudência quanto ao manejamento do trabalho de historia de vida junto a pessoas que apresentam perturbações da personalidade tão severas quanto às apresentadas por Jacky. Entretanto, é importante constatar quanto o trabalho de historia de vida levado por Jacky no seio do grupo teve um efeito continente em relação a sua estrutura caracterial durante sua estadia. Este paciente descrito como "psicopata", chegava, com efeito, sem atrasos nos encontros coletivamente fixados, respeitava escrupulosamente os compromissos assumidos no decorrer das sessões precedentes e fazia perfeitamente "o jogo" que lhe era proposto. Manter um paciente como Jacky em uma estrutura hospitalar durante dois meses quando ele podia a qualquer momento decidir sua saída não é evidentemente algo fácil. Sublinhemos que no decorrer de sua hospitalização, Jacky se encontrou de fato confrontado a um universo regido por regras institucionais que lembram as pressões sociais até então dificilmente suportáveis (chegar na hora, ir ao atelier, não sair sem "permissão", aceitar o regulamento...). Ora, Jacky parecia ter encontrado neste grupo um espaço de expressão e de diálogo que lhe permitia fazer por partes a ruptura com o que ele havia podido conhecer antes. Jacky não era mais aqui um marginal violento, rejeitado e que desejava ser rejeitado pela sociedade, mas uma pessoa em tratamento_que dividia o mesmo problema do álcool como outros participantes e que, por isso, podia contar sua historia singular ao grupo.

Enfim, este trabalho de historia de vida não tem pretensão de modificar a estrutura profunda da personalidade do sujeito. Ele pode, no máximo, se revelar por vezes propedêutico para outros dispositivos, muito mais pesados, como o tratamento psicanalítico, por exemplo. Todavia, pela pregnancia das perturbações adictivas e pela estrutura de personalidade subjacente de pessoas como Jacky, o tratamento analítico, quando ele é considerado, não pode ser utilizado em primeira intenção e ajustes do tratamento tipo devem ser propostos.

Em resumo, apesar dos seus limites, a abordagem historia de vida me parece poder permitir acompanhar as pessoas alcoólicas vitimas e/ou autores de violências. Com efeito, além dos desafios de conhecimento ligados ao uso destas práticas, a abordagem historia de vida utilizada em grupo, sob reserva de ter sido cuidadosamente contratualizada com os participantes, permite também pesquisar respostas democráticas que se apóiam sobre o respeito do individuo e sobre a reativação do laço entre si e o outro. Podemos nos autorizar aqui a um breve desvio filosófico para medir o alcance antropológico destes fatores. Ricoeur (1991), examinando o alcance do segundo imperativo categórico Kantien ${ }^{11}$ aborda estas questões afirmando a primazia da ética sobre a moral e evoca o "cuidado de si", o "cuidado do outro" e o "cuidado da instituição" para qualificar a visada ética. Para Ricoeur, a moral cobre "o lado obrigatório, marcado por normas, obrigações, proibições caracterizadas ao mesmo tempo por uma exigência da universalidade e por um efeito de pressão. “ (p.256). De outra maneira, a ética acentua "a visada de uma vida cumprida sob o signo das ações estimadas boas"(p.256). Assim, a visada ética pode ser definida pela formula seguinte: "Visada da vida boa, com e para os

\footnotetext{
11 "Aja sempre de tal maneira que tu tratas a humanidade em tua própria pessoa e na do outro, não somente como um meio, mas sempre também como um fim em si”.
} 
outros, em instituições justas"(p.259). O outro, seja vitima ou carrasco, não pode então ser instrumentalizado em vista de nossos próprios fins: "O reconhecimento por um locutor da capacidade de seu destinatário de se designar ele mesmo como a origem de seu discurso encontra um paralelo em um reconhecimento mutuo do mesmo tipo (...) Como eu, você é o agente de suas ações. Mais precisamente, você não é somente o receptor de minhas ações, você não as sofre somente, mas, como eu, você é também um agente" (Ricoeur, 1993.). É este movimento dialógico de reciprocidade que funda a articulação entre cuidado de si e cuidado do outro numa atitude de solicitude que permite articular a estima de si e sentido ético da justiça em beneficio do exercício do julgamento prudencial tão importante no tratamento destes fenômenos de violências.

\section{REFERÊNCIAS}

Bourdieu, P. (1979). La distinction. Paris: Editions de Minuit.

Debray, Q. (1994) Les conséquences comportementales de l'ivresse. En Pelicier (Dir). Les ivresses. (pp. 74-84) Paris: L'Esprit du Temps.

De Gaulejac, V. (1987). La névrose de classe. Paris: Hommes et groupes.

De Gaulejac, V. \& Roy S. (Dir.) (1993). Sociologies cliniques. Paris/Marseille: Hommes et perspectives/Desclée de Brouwer.
Delory Momberger, C. (2003) Biographie et éducation. Paris :Anthropos.

Fouquet, P. (1956, com J. Clavreul) Une thérapeutique de l'alcoolisme. (2 éme éd.), 1965, Paris: Le Courrier du Livre.

Jellineck, E. M. (1946). Phases in the drinking history of alcoholics. New Haven: Hillhouse Press.

Jellineck E. M. (1960). The disease concept of alcoholism. New Haven: Hillhouse Press.

Klein, M. (1948). Sur la théorie de l'angoisse et de la culpabilité. En M Klein Développements de la psychanalyse. Paris : P.U.F.

Legrand, M. (1993). L'approche biographique. Paris/Marseille: Hommes et perspectives/Desclée de Brouwer.

Legrand, M. (1997). Le sujet alcoolique: essai de psychologie dramatique. Paris: Desclée de Brouwer.

Maisondieu, J. (1992). "Les alcooléens". Paris: Bayard éditions.

Niewiadomski, C. (2000) Histoires de vie et alcoolisme. Paris: Seli Arslan.

Niewiadomski, C. \& de Villers G (Dir.) (2002). Souci et soin de soi: liens et frontières entre histoires de vie, psychothérapie et psychanalyse. Paris: L'Harmattan.

Ricoeur, P. (1991). Lectures 1 : autour du politique. Paris: Le Seuil.

Ricoeur, P. (1993). Le "soi” digne d'estime et de respect. Le respect. Revue Autrement, 10, 88-99.

Recebido em 22/06/2004 Aceito em 28/09/2004

Endereço para correspondência: 77, rue de la Prévôté, 59650, Ville nueve d’Ascq, France. E-mail: niewia@aol.com. 